\title{
Obesity: Nutrition and Genetics-A Short Narrative Review
}

\author{
José M. Tallon'1, Janine Narciso², Ana Barros ${ }^{1}$, Ana Pereira ${ }^{3,4}$, Aldo M. Costa ${ }^{2,4,5}$, António J. Silva ${ }^{1,4}$ \\ ${ }^{1}$ University of Trás-os-Montes e Alto Douro, Vila Real, Portugal \\ ${ }^{2}$ University of Beira Interior, Covilhã, Portugal \\ ${ }^{3}$ Polytechnic Institute of Setúbal, Superior School of Education, Setúbal, Portugal \\ ${ }^{4}$ Research Centre in Sports, Health and Human Development, CIDESD, Vila Real, Portugal \\ ${ }^{5}$ Health Science Research Center, CICS-UBI, Covilhã, Portugal \\ Email: ajsilva@utad.pt
}

How to cite this paper: Tallon, J.M., Narciso, J., Barros, A., Pereira, A., Costa, A.M. and Silva, A.J. (2018) Obesity: Nutrition and Genetics-A Short Narrative Review. Health, 10, 1779-1788.

https://doi.org/10.4236/health.2018.1012134

Received: December 6, 2018

Accepted: December 26, 2018

Published: December 29, 2018

Copyright (c) 2018 by authors and Scientific Research Publishing Inc. This work is licensed under the Creative Commons Attribution International License (CC BY 4.0).

http://creativecommons.org/licenses/by/4.0/

\begin{abstract}
Obesity has become a major global health challenge and it is a risk factor for the development of several comorbid conditions. Additionally, obesity has considerable economic consequences. Obesity is a multifactorial condition that arises from independent influences of genetic and social-environmental factors on food intake and physical activity. It has been difficult to establish clear associations between weight status and the intake of single foods or food groups. In most people, the predisposition to obesity has a polygenic basis, which means that obesity will develop if an individual has several polygenic variants that increase body weight. The FTO gene was the first GWAS-identified obesity-susceptibility gene and since then other polygenic variants that are associated with BMI and dietary intake have also been identified. However, this is still an active area of research as more polygenetic variants await discovery.
\end{abstract}

\section{Keywords}

Obesity, Nutrition, Genetics

\section{Introduction}

Obesity has become a major global health challenge [1]. A recent study, that estimated Body Mass Index (BMI) trends in 200 countries and territories in people 5 years and older, reported that the worldwide number of adult women with obesity increased from 69 million in 1975 to 390 million in 2016, while the number of men with obesity increased from 31 million to 281 million, over the same period. The study also shown that the rising trends in both, children's and adoles- 
cent's BMI appear to be leveling off in many high-income countries, albeit at high levels [2].

Obesity is associated with higher mortality and it is a risk factor for the development of several comorbid conditions such as diabetes, hypertension and cardiovascular disease [3] [4] [5]. In addition, obesity also has considerable economic consequences. The direct healthcare costs of obesity are high and obese individuals have a $36 \%$ increase in annual health-care costs and a $77 \%$ increase in medication costs, in comparison with their average weight counterparts [4]. Moreover, obesity has several indirect costs caused by the reduction of productivity and absenteeism due to illness or disability and early premature mortality [6].

In this short review we will address the classification, etiology and role of genetics and nutrition in obesity.

\section{Classification and Etiology}

Obesity is defined as abnormal or excessive fat accumulation that may impair health [7]. It is defined in terms BMI, which constitutes a proxy of body fat. [8] For adults, a BMI between $25 \mathrm{~kg} / \mathrm{m}^{2}$ and $29.9 \mathrm{~kg} / \mathrm{m}^{2}$ and a BMI greater than or equal to $30 \mathrm{~kg} / \mathrm{m}^{2}$ define overweight and obesity, respectively [7]. For children, age and sex-specific BMI cut-off points are used to classify overweight and obesity [9]. According to the location of the adipose tissue deposition, two different types of obesity can be defined: android obesity - in which adipose tissue accumulation around the abdomen predominates; and gynoid obesity-in which adipose tissue accumulation occurs in the femoral region [10] [11]. Generally, an increase in both the number and the size of adipocytes is observed in obesity [10].

The excessive storage of fat that occurs in obesity, eventually leads to the release of excessive fatty acids that provoke lipotoxicity, since lipids and their metabolites create oxidant stress to the endoplasmic reticulum and mitochondria. This will affect both, the adipose and the non-adipose tissue, accounting for obesity's impact in several organs that drive a range of pathological outcomes including hypertension, type 2 diabetes and an increased risk of cardiovascular disease, that eventually translates in a reduced life expectancy [12] [13]. The multiple health consequences of obesity are shown in Figure 1.

Even though substantial advances have been made regarding the development and progression of obesity, our understanding of its etiology is still incomplete [12]. Ross et al. [15] conducted a review of reviews regarding the causes of obesity in children and adults and concluded that there is no consensus in the literature regarding the specific factors that contribute to obesity. Understanding the etiology of obesity presents a substantial challenge due its complexity and interactions between several factors. Therefore, social ecological models have been proposed for understanding the etiology of obesity, as they are useful in examining a wide range of factors that contribute to a complex health issue [16]. 


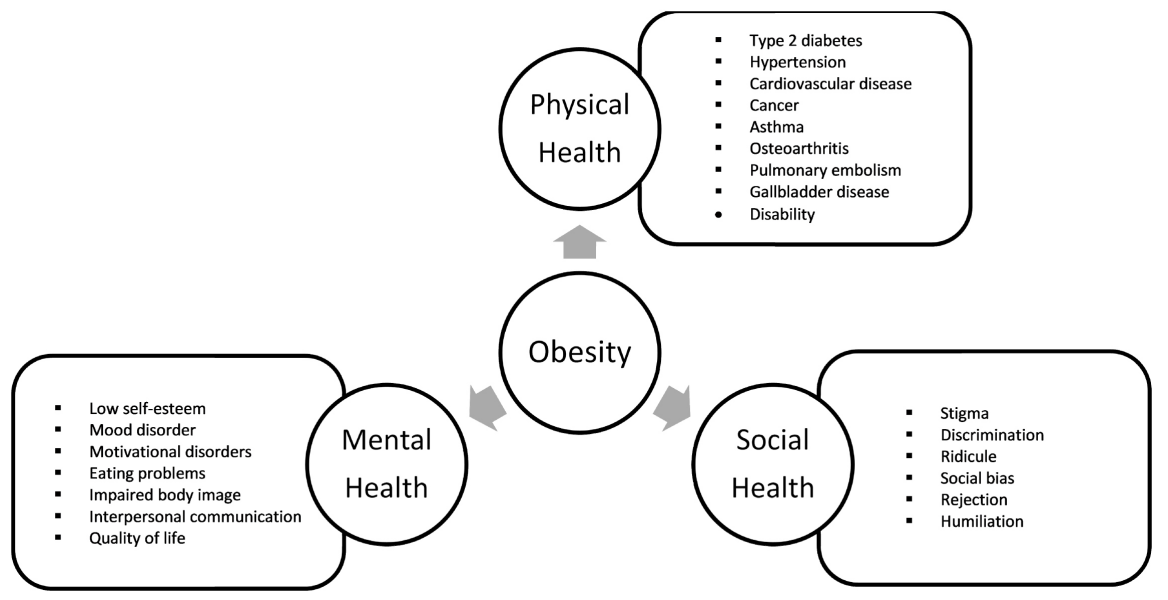

Figure 1. The multiple consequences of obesity on different dimensions of health [14].

The conceptual model proposed by Faith and Kral [17] hypothesizes that genetic and social-environmental factors lead to the development of obesity through their independent influences on food intake and physical activity. These intermediary behavioral variables may induce a positive energy balance that, if sustained over time, will promote obesity.

\section{Nutrition and Obesity}

At its most basic level, obesity results from a state of positive energy balance, where energy intake surpasses energy expenditure [18]. Human evolution has favored an accumulation of genes variants that result in an increased energy deposition as fat, in order to enhance survival to ancestral famine [19]. This leaves humans susceptible to an environment that facilitates overconsumption of energy-easy access to a wide variety of inexpensive energy dense foods and increased portion sizes; and promotes a reduction of energy expenditure by reducing physical activity—reduction in jobs requiring physical labor, reduced opportunities for physical activity and increased time spent in sedentary activities [20]. Thus, worldwide, a rise of almost $400 \mathrm{kcal}$ per person per day has been reported between 1969/71 and 1999/2001 [21].

However, not all calories are equal [5] and there has been an ongoing debate about the optimal macronutrient content of the diet in relation to obesity. To date, multiple studies suggest that little difference exist in body weight and health outcomes between diets that differ markedly in macronutrients composition. However, diet macronutrient composition may affect long-term weight loss [22].

Regarding specific types of foods, fast food consumption, which is high in fat, energy density and has large portion sizes, has shown a positive association with increased BMI, although the findings are not entirely consistent [23]. The health effects of sugar-sweetened beverages (SSB) have also received substantial attention from the scientific and public communities [24]. A recent systematic review, that assessed the recent evidence (2013 to 2015) regarding the impact of SSB on obesity in both, children and adults concluded that SSB consumption is posi- 
tively associated with or has an effect on obesity. The review included 26 prospective studies, of which 25 showed a positive association between SSB consumption and weight/BMI and 4 randomized controlled trials, of which 3 showed that SSB consumption had an effect on BMI/BMI z-score [25]. The association between dairy products intake and obesity remains controversial [26] [27] [28].

Overall, it has been difficult to establish clear associations between weight status and the intake of single foods or food groups [17]. Consequently, the association between several characteristics of dietary behavior and obesity have been studied, as they may reflect the joint effect of several foods and nutrients. It has been hypothesized that eating several small meals a day will improve fat loss and help achieve weight maintenance [29]. Data to support this hypothesis has been mainly provided by observational research [30]. However, in 2015 a meta-analysis that evaluated the experimental evidence on meal frequency with respect to changes in fat mass and lean mass in adults reported that eating frequency was positively associated with reductions in fat mass and body fat percentage. It is important to denote, however that after a sensitivity analysis of the data was done, the positive findings were the product of a single study [29]. Another eating behavior that is frequently advocated for controlling food intake and therefore body weight is eating rate. A recent meta-analysis found that eating fast is positively associated with excess body weight, with the mean difference in BMI between those individuals who ate faster and those who ate slowly being $1.78 \mathrm{~kg} / \mathrm{m}^{2}$ [31].

It also been suggested that deficiency levels of certain micronutrients may be associated with obesity, as micronutrients deficiencies have been observed in obese individuals worldwide [32] [33]. However, it is not well understood, whether a causal relationship exists, and if so, what is the direction of causality [32]. Results from a Chinese 26-week randomized, double-blinded, placebo-controlled intervention study have shown that in comparison with the placebo group, the group that received a 29-ingredient multivitamin and mineral supplementation had significant reductions in body weight, BMI and fat mass $(\mathrm{p}<0.01)$. While the supplementation of calcium alone (162 $\mathrm{mg} /$ day) only improved lipid profiles, with the calcium group having a significantly higher HDL-C $(\mathrm{p}<0.01)$ and a significantly lower LDL-C $(\mathrm{p}<0.05)$ at 26 weeks when compared with the placebo group [34]. However, further well-designed experimental studies are needed to understand the role of micronutrients on obesity.

\section{The Genetics of Obesity}

For several decades it has been know that familial factors had an important role in the development of obesity and that the genetic basis was behind much of those factors [35]. However, the major piece in the puzzle of obesity genetics was published in December 1994, when the leptin (a cytokine-like polypeptide produced primarily in the white adipose tissue, that controls food intake trough the activation of hypothalamic receptors [10] [36]) gene was cloned, triggering a 
revolution in the understanding of the biology of obesity [37].

Prominence shifted from the question of whether genetics plays a role in human obesity to which specific genes are responsible [38]. In 2005, according to the $12^{\text {th }}$ Update of Human Obesity Gene Map, 176 human obesity cases due to single-gene mutations in 11 different genes had been identified and 50 loci related to Mendelian syndromes relevant to obesity in humans had been mapped to a genomic region. Additionally, 426 studies reported positive associations between obesity and 127 candidate genes [39].

Twin studies, alongside family and adoption studies have provided evidence that a moderate to high heritability for BMI exists, however monogenic causes of obesity are rare [40]. In most people, the genetic mechanisms involved in the predisposition to obesity are polygenetic and more than 100 "polygenes" harboring genetic variants associated with body weight regulation have been identified. This means that obesity will develop if an individual harbor several polygenic variants that increase body weight. However, the same variants, although at a lower frequency, can also be found in normal weight individuals [41]. A polygenic basis of obesity implies that a specific set of polygenic variants relevant for obesity in one individual will likely differ in another obese individual [19].

Recent progress in the clarification of polygenic predisposition to obesity points to an important role of the central nervous system in body weight regulation [42], as many of the genes located within or near the obesity-associated regions are highly expressed in the central nervous system and appear to be involved in appetite, satiety, energy expenditure and behavior [43]. The FTO gene-the first genome-wide association studies (GWAS)-identified obesity-susceptibility gene [44] - is highly expressed in the hypothalamus, pituitary and adrenal glands that are implicated in body weight and satiety regulation [45]. Several polymorphisms in the FTO gene have been associated with obesity in both, children and adults [46]. A common obesity-risk variant rs9939609 in the FTO gene has been associated with reduced satiety [47] and higher energy intake in adults [48]. Another strong obesity candidate gene is the $M C 4 R$, which is expressed in neurons in the hypothalamus and is essential for regulation of food intake and energy expenditure [45] [49]. The MCAR rs17782313 polymorphism has been widely studied and found to be significantly associated with obesity risk (OR = $1.18,95 \% \mathrm{CI}=1.15-1.21, \mathrm{p}<0.001)$ in a systematic review and meta-analysis by Xi et al. [50]. The exact mechanism by which rs17782313 polymorphism may be associated with obesity is still unknown [51], however this variant has been associated with increased snacking and increased hunger in adults [52]. Contrarywise, a recent systematic review found limited significant evidence regarding the association between higher total energy intake and this polymorphism [53].

Other obesity genes identified by GWAS, such as, KCTD15, MTCH2, NEGR1, $B D N F$, have also been associated with dietary intake and BMI [54].

\section{Final Considerations}

Obesity is a complex polygenic disease that arises from an interaction between 
multiple genetic, environmental and behavioral factors, making obesity research extremely challenging. A better understanding of the association between dietary habits/behaviors and the risk of developing obesity is necessary as it will help tailor new strategies to prevent and treat obesity. The GWAS revolutionized the field of genetics allowing the detection of variants with small effect sizes [19], and therefore leading to the discovery of obesity polygenetic basis. This is still an active area of research as more polygenetic variants await discovery, allowing new etiological pathways to be discovered that in turn, will provide the development of novel therapies for the treatment of obesity. A future promising research direction is the management of obesity using genotypic information in "personalized nutrition".

\section{Conflicts of Interest}

The authors declare no conflicts of interest regarding the publication of this paper.

\section{References}

[1] Ng, M., Fleming, T., Robinson, M., Thomson, B., Graetz, N., Margono, C., et al. (2014) Global, Regional, and National Prevalence of Overweight and Obesity in Children and adults During 1980-2013: A Systematic Analysis for the Global Burden of Disease Study 2013. Lancet, 384, 766-781. https://doi.org/10.1016/S0140-6736(14)60460-8

[2] Abarca-Gómez, L., Abdeen, Z.A., Hamid, Z.A., Abu-Rmeileh, N.M., Acosta-Cazares, B., Acuin, C., et al. (2017) Worldwide Trends in Body-Mass Index, Underweight, Overweight, and Obesity from 1975 to 2016: A Pooled Analysis of 2416 Population-Based Measurement Studies in 128.9 Million Children, Adolescents, and Adults. Lancet, 390, 2627-2642. https://doi.org/10.1016/S0140-6736(17)32129-3

[3] Jarolimova, J., Tagoni, J. and Stern, T.A. (2013) Obesity: Its Epidemiology, Comorbidities, and Management. Primary Care Companion for CNS Disorders, 15 PCC.12f01475. https://doi.org/10.4088/PCC.12f01475

[4] Apovian, C.M. (2016) Obesity: Definition, Comorbidities, Causes, and Burden. American Journal of Managed Care, 22, s176-s185.

[5] Gadde, K.M., Martin, C.K., Berthoud, H.-R. and Heymsfield, S.B. (2018) Obesity. Journal of the American College of Cardiology, 71, 69-84. https://doi.org/10.1016/j.jacc.2017.11.011

[6] Dee, A., Kearns, K., O’Neill, C., Sharp, L., Staines, A., O’Dwyer, V., et al. (2014) The Direct and Indirect Costs of Both Overweight and Obesity: A Systematic Review. BMC Research Notes, 7, 242. https://doi.org/10.1186/1756-0500-7-242

[7] World Health Organization (2018) Obesity and Overweight [Internet]. http://www.who.int/news-room/fact-sheets/detail/obesity-and-overweight

[8] Müller, M.J. and Geisler, C. (2017) Defining Obesity as a Disease. European Journal of Clinical Nutrition, 71, 1256-1258. https://doi.org/10.1038/ejcn.2017.155

[9] Mullin, G., Cheskin, L. and Matarese, L. (2014) Integrative Weight Management. Springer, New York. https://doi.org/10.1007/978-1-4939-0548-5

[10] Clément, K. and Ferré, P. (2003) Genetics and the Pathophysiology of Obesity. Pediatric Research, 53, 721-725. 
https://doi.org/10.1203/01.PDR.0000059753.61905.58

[11] Kopelman, P.G., Caterson, I.D. and Dietz, W.H., Eds. (2009) Clinical Obesity in Adults and Children. 3rd Edition, Wiley-Blackwell, Oxford.

[12] Mingrone, G. and Castagneto, M. (2015) The Pathophysiology of Obesity. In: Lucchese M. and Scopinaro, N., Eds., Minimally Invasive Bariatric and Metabolic Surgery, Springer International Publishing, Cham, 17-23. https://doi.org/10.1007/978-3-319-15356-8_3

[13] Redinger, R.N. (2007) The Pathophysiology of Obesity and Its Clinical Manifestations. Gastroenterology \& Hepatology, 3, 856-863.

[14] Kelishadi, R. (2014) Health Impacts of Obesity. Pakistan Journal of Medical Sciences, 31, 212-214. https://doi.org/10.12669/pjms.311.7033

[15] Ross, S.E., Flynn, J..I. and Pate, R.R. (2016) What Is Really Causing the Obesity Epidemic? A Review of Reviews in Children and Adults. Journal of Sports Sciences, 34, 1148-1153. https://doi.org/10.1080/02640414.2015.1093650

[16] Lytle, L.A. (2009) Examining the Etiology of Childhood Obesity: The IDEA Study. American Journal of Community Psychology, 44, 338-349. https://doi.org/10.1007/s10464-009-9269-1

[17] Faith, M.S. and Kral, T.V.E. (2006) Social Environment and Genetic Influences on Obesity and Obesity-Promoting Behaviors: Fostering Research Integration. In: Hernandez, L. and Blazer, D., Eds., Genes, Behavior, and the Social Environment: Moving beyond the Nature/ Nurture Debate, National Academies Press, Washington DC, 237-238.

[18] Hill, J.O., Wyatt, H.R. and Peters, J.C. (2012) Energy Balance and Obesity. Circulation, 126, 126-132. https://doi.org/10.1161/CIRCULATIONAHA.111.087213

[19] Hinney, A., Vogel, C.I.G. and Hebebrand, J. (2010) From Monogenic to Polygenic Obesity: Recent Advances. European Child \& Adolescent Psychiatry, 19, 297-310. https://doi.org/10.1007/s00787-010-0096-6

[20] Hill, J.O., Wyatt, H.R., Reed, G.W. and Peters, J.C. (2003) Obesity and the Environment: Where Do We Go from Here? Science, 299, 853-855. https://doi.org/10.1126/science.1079857

[21] Kearney, J. (2010) Food Consumption Trends and Drivers. Philosophical Transactions of the Royal Society B Biological Sciences, 365, 2793-2807. https://doi.org/10.1098/rstb.2010.0149

[22] Fleming, J.A. and Kris-Etherton, P.M. (2016) Macronutrient Content of the Diet: What Do We Know about Energy Balance and Weight Maintenance? Current $O b$ esity Reports, 5, 208-213. https://doi.org/10.1007/s13679-016-0209-8

[23] Rosenheck, R. (2008) Fast Food Consumption and Increased Caloric Intake: A Systematic Review of a Trajectory towards Weight Gain and Obesity Risk. Obesity Reviews, 9, 535-547. https://doi.org/10.1111/j.1467-789X.2008.00477.x

[24] Imamura, F., O’Connor, L., Ye, Z., Mursu, J., Hayashino, Y., Bhupathiraju, S.N., et al. (2016) Consumption of Sugar Sweetened Beverages, Artificially Sweetened Beverages, and Fruit Juice and Incidence of Type 2 Diabetes: Systematic Review, Meta-Analysis, and Estimation of Population Attributable Fraction. British Journal of Sports Medicine, 50, 496-504. https://doi.org/10.1136/bjsports-2016-h3576rep

[25] Luger, M., Lafontan, M., Bes-Rastrollo, M., Winzer, E., Yumuk, V. and Farpour-Lambert, N. (2017) Sugar-Sweetened Beverages and Weight Gain in Children and Adults: A Systematic Review from 2013 to 2015 and a Comparison with Previous Studies. Obesity Facts, 10, 674-693. 
https://doi.org/10.1159/000484566

[26] Chen, M., Pan, A., Malik, V.S. and Hu, F.B. (2012) Effects of Dairy Intake on Body Weight and Fat: A Meta-Analysis of Randomized Controlled Trials. The American Journal of Clinical Nutrition, 96, 735-747. https://doi.org/10.3945/ajcn.112.037119

[27] Wang, W., Wu, Y. and Zhang, D. (2016) Association of Dairy Products Consumption with Risk of Obesity in Children and Adults: A Meta-Analysis of Mainly Cross-Sectional Studies. Annals of Epidemiology, 26, 870-882.e2. https://doi.org/10.1016/j.annepidem.2016.09.005

[28] Schwingshackl, L., Hoffmann, G., Schwedhelm, C., Kalle-Uhlmann, T., Missbach, B., Knüppel, S., et al. (2016) Consumption of Dairy Products in Relation to Changes in Anthropometric Variables in Adult Populations: A Systematic Review and Meta-Analysis of Cohort Studies. PLoS ONE, 11, e0157461. https://doi.org/10.1371/journal.pone.0157461

[29] Qi, L. (2014) Personalized Nutrition and Obesity. Annals of Medicine, 46, 247-252. https://doi.org/10.3109/07853890.2014.891802

[30] Wang, Y.-Q., Zhang, Y.-Q., Zhang, F., Zhang, Y.-W., Li, R. and Chen, G.-X. (2016) Increased Eating Frequency Is Associated with Lower Obesity Risk, but Higher Energy Intake in Adults: A Meta-Analysis. International Journal of Environmental Research and Public Health, 13, 603. https://doi.org/10.3390/ijerph13060603

[31] Ohkuma, T., Hirakawa, Y., Nakamura, U., Kiyohara, Y., Kitazono, T. and Ninomiya, T. (2015) Association between Eating Rate and Obesity: A Systematic Review and Meta-Analysis. International Journal of Obesity, 39, 1589-1596.

https://doi.org/10.1038/ijo.2015.96

[32] García, O.P., Long, K.Z. and Rosado, J.L. (2009) Impact of Micronutrient Deficiencies on Obesity. Nutrition Reviews, 67, 559-572. https://doi.org/10.1111/j.1753-4887.2009.00228.x

[33] Astrup, A. and Bügel, S. (2010) Micronutrient Deficiency in the Aetiology of Obesity. International Journal of Obesity, 34, 947-948. https://doi.org/10.1038/ijo.2010.81

[34] Li, Y., Wang, C., Zhu, K., Feng, R.N. and Sun, C.H. (2010) Effects of Multivitamin and Mineral Supplementation on Adiposity, Energy Expenditure and Lipid Profiles in Obese Chinese Women. International Journal of Obesity, 34, 1070-1077. https://doi.org/10.1038/ijo.2010.14

[35] Nirmala, A., Reddy, B.M. and Reddy, P.P. (2008) Genetics of Human Obesity: An Overview. International Journal of Human Genetics, 8, 217-226. https://doi.org/10.1080/09723757.2008.11886032

[36] Harris, R.B.S. (2014) Direct and Indirect Effects of Leptin on Adipocyte Metabolism. Biochimica et Biophysica Acta-Molecular Basis of Disease, 1842, 414-423. https://doi.org/10.1016/j.bbadis.2013.05.009

[37] Bray, G.A. and York, D.A. (1997) Leptin and Clinical Medicine: A New Piece in the Puzzle of Obesity. The Journal of Clinical Endocrinology \& Metabolism, 82, 2771-2776. https://doi.org/10.1210/jcem.82.9.4224

[38] Comuzzie, A.G. and Allison, D.B. (1998) The Search for Human Obesity Genes. Science, 280, 1374-1377. https://doi.org/10.1126/science.280.5368.1374

[39] Rankinen, T., Zuberi, A., Chagnon, Y.C., Weisnagel, S.J., Argyropoulos, G., Walts, B., et al. (2006) The Human Obesity Gene Map: The 2005 Update. Obesity, 14, 529-644. https://doi.org/10.1038/oby.2006.71

[40] Ells, L.J., Demaio, A. and Farpour-Lambert, N. (2018) Diet, Genes, and Obesity. 
BMJ, 360, k7. https://doi.org/10.1136/bmj.k7

[41] Hinney, A. and Giuranna, J. (2018) Polygenic Obesity. In: Freemark, M.S., Ed., Pediatric Obesity, Springer International Publishing, Cham, 183-202.

https://doi.org/10.1007/978-3-319-68192-4_10

[42] Choquet, H. and Meyre, D. (2011) Genetics of Obesity: What Have We Learned? Current Genomics, 12, 169-179.

[43] Herrera, B.M. and Lindgren, C.M. (2010) The Genetics of Obesity. Current Diabetes Reports, 10, 498-505. https://doi.org/10.1007/s11892-010-0153-z

[44] Loos, R.J.F. and Yeo, G.S.H. (2014) The Bigger Picture of FTO-The First GWAS-Identified Obesity Gene. Nature Reviews Endocrinology, 10, 51-61. https://doi.org/10.1038/nrendo.2013.227

[45] Kirac, D., Kasimay Cakir, O., Avcilar, T., Deyneli, O., Kurtel, H., Yazici, D., et al. (2016) Effects of $M C A R, F T O$, and $N M B$ Gene Variants to Obesity, Physical Activity, and Eating Behavior Phenotypes. IUBMB Life, 68, 806-816.

https://doi.org/10.1002/iub.1558

[46] Peng, S., Zhu, Y., Xu, F., Ren, X., Li, X. and Lai, M. (2011) FTO Gene Polymorphisms and Obesity Risk: A Meta-Analysis. BMC Medicine, 9, 71. https://doi.org/10.1186/1741-7015-9-71

[47] Wardle, J., Carnell, S., Haworth, C.M.A., Farooqi, I.S., O’Rahilly, S. and Plomin, R. (2008) Obesity Associated Genetic Variation in FTO Is Associated with Diminished Satiety. The Journal of Clinical Endocrinology \& Metabolism, 93, 3640-3643. https://doi.org/10.1210/jc.2008-0472

[48] Speakman, J.R., Rance, K.A. and Johnstone, A.M. (2008) Polymorphisms of the FTO Gene Are Associated with Variation in Energy Intake, but Not Energy Expenditure. Obesity, 16, 1961-1965. https://doi.org/10.1038/oby.2008.318

[49] Muñoz Yáñez, C., García Vargas, G.G. and Pérez-Morales, R. (2017) Monogenic, Polygenic and Multifactorial Obesity in Children: Genetic and Environmental Factors. Austin Journal of Nutrition \& Metabolism, 4, Article ID: 1052.

[50] Xi, B., Chandak, G.R., Shen, Y., Wang, Q. and Zhou, D. (2012) Association between Common Polymorphism near the MC4R Gene and Obesity Risk: A Systematic Review and Meta-Analysis. PLoS ONE, 7, e45731. https://doi.org/10.1371/journal.pone.0045731

[51] Khalilitehrani, A., Qorbani, M., Hosseini, S. and Pishva, H. (2015) The Association of MC4R rs17782313 Polymorphism with Dietary Intake in Iranian Adults. Gene, 563, 125-129. https://doi.org/10.1016/j.gene.2015.03.013

[52] Stutzmann, F., Cauchi, S., Durand, E., Calvacanti-Proença, C., Pigeyre, M., Hartikainen, A.-L., et al. (2009) Common Genetic Variation near MC4R Is Associated with Eating Behaviour Patterns in European Populations. International Journal of Obesity, 33, 373-378. https://doi.org/10.1038/ijo.2008.279

[53] Drabsch, T., Gatzemeier, J., Pfadenhauer, L., Hauner, H. and Holzapfel, C. (2018) Associations between Single Nucleotide Polymorphisms and Total Energy, Carbohydrate, and Fat Intakes: A Systematic Review. Advances in Nutrition, 9, 425-453. https://doi.org/10.1093/advances/nmy024

[54] Bauer, F., Elbers, C.C., Adan, R.A., Loos, R.J., Onland-Moret, N.C., Grobbee, D.E., et al. (2009) Obesity Genes Identified in Genome-Wide Association Studies Are Associated with Adiposity Measures and Potentially with Nutrient-Specific Food Preference. The American Journal of Clinical Nutrition, 90, 951-959.

https://doi.org/10.3945/ajcn.2009.27781 


\section{Abbreviations}

BMI: body mass index; SSB: sugar-sweetened beverages; HDL-C: high-density lipoprotein cholesterol; LDL-C: low-density lipoprotein cholesterol; FTO: fat mass and obesity associated; GWAS: genome-wide association studies; MC4R: melanocortin 4 receptor; KCTD15: potassium channel tetramerization domain-containing 15; $M T C H 2$ : mitochondrial carrier homolog 2; NEGR1: neuronal growth regulator 1; $B D N F$ : brain-derived neurotrophic factor. 